\title{
Waist-to-height ratio index for predicting incidences of hypertension: the ARIRANG study
}

\author{
Jung Ran Choi ${ }^{1}$, Sang Baek Koh ${ }^{1,2^{*}}$ and Eunhee $\mathrm{Choi}^{3}$
}

\begin{abstract}
Background: Several anthropometric indices such as body mass index (BMI) and waist circumference (WC) have been examined as indicators of cardiovascular diseases, in both adults and children. However, the waist-to-height ratio $(\mathrm{WHtR})$ is considered a better predictor for the detection of cardiovascular risk factors, than BMI. We investigated the association between the WHtR and incident hypertension.

Methods: A total of 1718 participants, aged 39-72 years, were recruited in this longitudinal study. Participants were divided into 2 groups according to the development of hypertension during 2005-2008 (baseline) and 2008-2011 (follow-up). Logistic regression models were used to evaluate the WHtR as a significant predictor of hypertension.

Results: During the 2.8 years of follow-up, 185 new cases of hypertension (10.8\%) were diagnosed, with an incidence rate of approximately $4 \%$ per year. The WHtR was significantly higher in the participants who had developed hypertension than in those who had not $(0.54 \pm 0.05$ vs. $0.51 \pm 0.05, p<0.001)$. After adjusting for age, sex, smoking status, alcohol intake, regular exercise status, total cholesterol, and systolic blood pressure, at the baseline, the logistic regression analysis indicated that the participants with the highest quartile of the $\mathrm{WHtR}(\mathrm{WHt} \geq 0.54)$ were 4.51 times more likely to have hypertension than those with the lowest quartile (odds ratio $4.51 ; 95 \%$ confidence interval $2.41-8.43 ; p<.0001$ ). The area under the curve for the WHtR, in identifying hypertension risk, was significantly greater than that for the BMI $(p=0.0233)$.

Conclusion: A positive association between WHtR and the incidence of hypertension was observed in Korean adults. The findings of the present community-based prospective study suggest that the WHtR may be a better predictor of incident hypertension.
\end{abstract}

Keywords: Waist-to-height ratio, Hypertension, Community-based prospective study, Predictor, Korean adults

\section{Background}

Owing to the increases in the incidences of obesity and lifestyle changes, the prevalence of cardiovascular diseases (CVDs), such as hypertension and diabetes, has been on the rise. It has been suggested that the prevention and regulation of hypertension and diabetes could substantially decrease the risk of CVD development [1, 2]. Hypertension is a one of the risk factors for obesity-related CVDs [3]. Several epidemiological reports have demonstrated an

\footnotetext{
* Correspondence: kohhj@yonsei.ac.kr

${ }^{1}$ Institute of Genomic Cohort, Yonsei University Wonju College of Medicine, Wonju, Republic of Korea

${ }^{2}$ Department of Preventive Medicine, Yonsei University Wonju College of

Medicine, Wonju, Republic of Korea

Full list of author information is available at the end of the article
}

upward trend in the link between the prevalence of increased blood pressure or hypertension and obesity [3-5].

Recently conducted cross-sectional studies have investigated the association of waist circumference (WC), waist-to-hip ratio (WHR), waist-to-height ratio (WHtR), and body mass index (BMI) with the prevalence of hypertension [2, 6-8]. However, in those studies, most of the anthropometric indices, such as BMI and WC, were used for the prediction of obesity-related outcomes such as central obesity, and were not constant between the genders and various ethnic groups [2, 3, 6-8]. In Japan, various cross-sectional studies have demonstrated a stronger association of WHtR with cardiovascular risk factors, compared to BMI and WC $[2,6,9]$. 
WHtR is a simple and practical tool used for the measurement of metabolic risk factors $[1,10,11]$. A systematic review inferred that WHtR may be beneficial, regardless of the age-, gender-, and ethnicity-specific values [12]. Studies have shown anthropometric indicators can predict hypertension in adolescents [11]. Additionally, it has been observed that obese children with a higher WHtR are more likely to have a higher cardiometabolic risk, and a single WHtR cut-off of 0.5 seems to be suitable for use in children as well as in adults, without age-related distinctions [1, 13, 14]. Recent reports investigated a WHtR cut-off value $\geq 0.5$ and confirmed that high adiposity was strongly connected with cardiovascular disease $[9,10,15-17]$. However, those cut-offs were established in Asian populations; in non-Asian populations, this association may be different $[18,19]$.

Nevertheless, only a few longitudinal studies have compared the appearance of anthropometric parameters in population-based cohorts [2, 4]. Therefore, it is not yet clear which anthropometric index has the strongest association with hypertension, in Asian populations. To further investigate which of the aforementioned indices is the best predictor of the risk of hypertension [20], we examined the population-specific association between WHtR and the incidence of hypertension, in this Korean prospective cohort study.

\section{Methods}

\section{Participants}

This study was conducted from the Korean Genome and Epidemiology Study on Atherosclerosis Risk of Rural Areas in the Korean General Population (KoGES-ARIRANG), a prospective cohort study to observe the prevalence, incidence and risk factors for chronic degenerative disorders. KoGES-ARIRANG included all adults who dwelled in rural areas of Wonju and Pyengchang, Gangwon-do in South Korea where demographic shifts are infrequent and the population can be followed long-term.

The baseline survey performed from November 2005 to January 2008, contained 5178 adults (2127 men and 3051 women) aged 40 to 70 years. All study subjects were participated in the first follow-up survey (April 2008 to January 2011), of whom 3862 (74.6\%) attended. The initial dataset consisted of 3862 participants, aged 39-72 years, on whom the follow-up survey, spanning 2.8 years, was performed. Of these participants, 2144 were excluded due to the presence of hypertension and missing data, especially data on WC and blood pressure. The final dataset comprised 1718 non-hypertensive participants, with a mean age of 53.53 years (Fig. 1). The participants were divided into 2 groups, according to the development of hypertension during 2005-2008 (baseline) and 2008-2011 (follow-up).

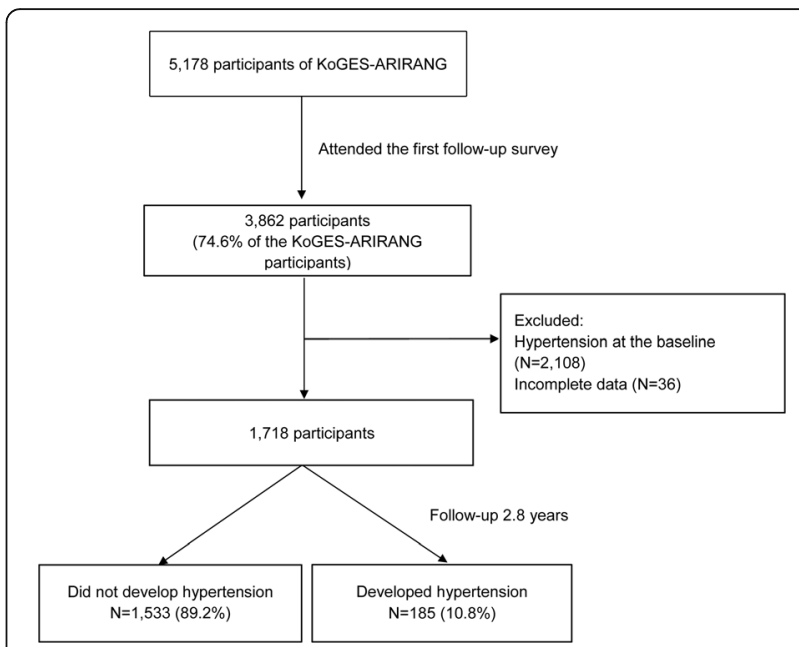

Fig. 1 Flow chart of the participants in the KoGES-ARIRANG study

This study was approved by the Institutional Review Board of the Wonju Christian Hospital, according to the Helsinki Declaration. All the participants provided informed written consent. Hypertension was defined as a $\mathrm{SBP} \geq 140 \mathrm{mmHg}$, and/or $\mathrm{DBP} \geq 90 \mathrm{mmHg}$, and/or current treatment with antihypertensive medications, at the baseline and follow-up surveys. All the participants were examined after fasting.

\section{Anthropometric and laboratory measurements}

Baseline anthropometric indices such as the BMI and WC, and several parameters were measured. In addition, lifestyle-related factors such as smoking, alcohol intake, and regular exercise status were also investigated. Height and weight were measured twice and then averaged. The WHtR was calculated as the WC $(\mathrm{cm})$ divided by the height $(\mathrm{cm})$. The BMI was calculated by dividing the weight $(\mathrm{kg})$ by the square of the height $(\mathrm{m})$. The WC was measured in the horizontal plane at the mid-point between the anterior iliac crest and the inferior margin of the rib, using a tape measure (SECA-200, SECA, Hamburg, Germany).

Systolic blood pressure (SBP) and diastolic blood pressure (DBP) were measured twice using a standardized mercury sphygmomanometer (Baumanometer, Copiague, NY), on the right arm, and then averaged.

Blood from the participants was extracted into a plain, siliconized glass tube, and serum was separated. Fasting glucose was measured using the hexokinase method. The serum concentrations of low-density lipoprotein (LDL) cholesterol, high-density lipoprotein (HDL) cholesterol, and triglycerides (TGs) were determined using the enzymatic calorimetric method (Advia 1650, Siemens, Tarrytown, NY).

Alcohol and smoking habits were estimated using self-questionnaires. Individuals who had smoked $\geq 100$ cigarettes in their lifetime were defined as current smokers, 
and those who had not smoked for $\geq 3$ months were defined as ex-smokers. An interview was performed to confirm the use of medications for hypertension, and the status of regular physical exercise.

\section{Statistical analysis}

All the data were analyzed using SPSS version 21.0 (SPSS Inc., Chicago, IL, USA). The baseline characteristics were examined using the chi-square test. To estimate which of the biomarkers was the best predictor of hypertension, we calculated the sensitivity, specificity and mean area under the receiver operator characteristics curve (AU-ROC) of the baseline BMI, WHR and WHtR, and their 95\% confidence intervals (CIs), using receiver operating characteristic curves in the group in which hypertension had newly developed. The population-specific risk of hypertension was compared among the quartiles of WHtR. The odds ratios (ORs) of hypertension and their 95\% CIs were calculated with reference to the first quartile of each of the measurements, using the logistic regression model. We adjusted for age, gender, alcohol consumption (current), smoking status (current), and physical exercise (yes or no). Additionally, we also adjusted for the baseline SBP, for the hypertension analysis, and the baseline total cholesterol (TC). $P<0.05$ was considered statistically significant.

\section{Results}

\section{Baseline characteristics}

A total of 1718 participants were included in this study. During the average 2.8-year follow-up, 185 participants $(10.8 \%)$ developed hypertension. Table 1 shows the mean \pm $\mathrm{SD}$, and proportion of the risk characteristics and anthropometric parameters in the participants, for the prediction of the risk of hypertension. The mean $\mathrm{WHtR}$ values were higher in the participants in whom hypertension development was observed than in those who did not develop hypertension $(0.54 \pm 0.05$ vs. $0.51 \pm 0.05, p<.0001)$. In the participants who developed hypertension, the baseline SBP and TC were $122.1 \pm 9.94 \mathrm{mg} / \mathrm{dl}$ and $204.30 \pm 34.83 \mathrm{mg} / \mathrm{dl}$, respectively, and these parameters were higher than in those who did not develop hypertension $(p<.0001$ vs. $p=0.0070$ ). There were no differences in the mean proportions, in terms of smoking habits and the regular exercise status, between the 2 groups (Table 1 ).

\section{Odds ratio for the development of hypertension, according to the WHtR}

After adjusting for age, gender, smoking status, alcohol intake, regular exercise, baseline TC, and SBP, the OR of the WHtR was found to be significantly associated with a 4.5-fold increase in the risk of hypertension. A higher WHtR, at the baseline, was positively and significantly associated, in a ratio-dependent manner, with the development of hypertension, in both the crude and adjusted
Table 1 Baseline characteristics of the study populations, according to the hypertension status at the follow-up

\begin{tabular}{|c|c|c|c|}
\hline & $\begin{array}{l}\text { Did not develop } \\
\text { hypertension }\end{array}$ & $\begin{array}{l}\text { Developed } \\
\text { Hypertension }\end{array}$ & $p$ \\
\hline N (\%) & $1533(89.2)$ & $185(10.8)$ & \\
\hline Age (yr) & $53.12 \pm 8.11$ & $56.87 \pm 8.01$ & $<.0001$ \\
\hline Gender (M) & $546(35.62 \%)$ & $84(45.41 \%)$ & 0.0091 \\
\hline Waist-to-height ratio & $0.51 \pm 0.05$ & $0.54 \pm 0.05$ & $<.0001$ \\
\hline Waist-to-hip ratio & $0.86 \pm 0.07$ & $0.89 \pm 0.05$ & $<.0001$ \\
\hline Weight (kg) & $59.92 \pm 9.25$ & $63.37 \pm 9.50$ & $<.0001$ \\
\hline BMI $\left(\mathrm{kg} / \mathrm{m}^{2}\right)$ & $23.72 \pm 2.90$ & $24.93 \pm 2.76$ & $<.0001$ \\
\hline SBP $(\mathrm{mmHg})$ & $117.17 \pm 11.03$ & $122.11 \pm 9.94$ & $<.0001$ \\
\hline $\mathrm{DBP}(\mathrm{mmHg})$ & $73.78 \pm 7.41$ & $75.54 \pm 6.66$ & 0.0021 \\
\hline TC (mg/dl) & $196.80 \pm 35.81$ & $204.30 \pm 34.83$ & 0.0070 \\
\hline TG (mg/dl) & $127.48 \pm 83.90$ & $142.52 \pm 85.12$ & 0.0216 \\
\hline $\mathrm{HDL}(\mathrm{mg} / \mathrm{dl})$ & $46.67 \pm 10.81$ & $45.92 \pm 10.87$ & 0.3737 \\
\hline LDL (mg/dl) & $115.18 \pm 30.98$ & $121.71 \pm 28.26$ & 0.0063 \\
\hline Fasting glucose (mg/dl) & $93.08 \pm 19.03$ & $94.49 \pm 13.87$ & 0.2127 \\
\hline Current smokers, n (\%) & $400(26.13 \%)$ & $57(31.15 \%)$ & 0.1466 \\
\hline Current drinkers, n (\%) & $617(40.38 \%)$ & $96(52.46 \%)$ & 0.0017 \\
\hline Regular exercise, n (\%) & $1074(70.29 \%)$ & $144(78.26 \%)$ & 0.0241 \\
\hline
\end{tabular}

$B M I$ body mass index, SBP systolic blood pressure, $D B P$ diastolic blood pressure, $T C$ total cholesterol, $T G$ triglyceride, $H D L$ high-density lipoprotein, $L D L$ low-density lipoprotein

conditional logistic regression models. The OR of hypertension for the highest vs. lowest quartile of WHtR was statistically significant (OR $4.51 ; 95 \%$ CI $2.41-8.43$ ); $p<.0001$ ) (Table 2).

\section{Comparison of the anthropometric indices for predicting the development of hypertension}

The mean AU-ROC of the WHtR was higher than that of the BMI (AUC $=0.662 ; 95 \% \mathrm{CI}, 0.625 \sim 0.700$, $p=0.0233$ ) (Table 3). Table 3 presents the AUC of each variable, for the presence of hypertension in Korean adults. According to the respective ROC curves, the WHtR had the highest AUC (AUC=0.662), followed by the WHR $(\mathrm{AUC}=0.648)$, BMI $(\mathrm{AUC}=0.623)$, and weight $(\mathrm{AUC}=$ 0.609). Figure 2 shows the ROC curves for the WHtR added SBP to predict the presence of hypertension in Korean adults.

\section{Discussion}

In the present study, an increased baseline WHtR was observed to be positively associated with the development of hypertension, over a median follow-up period of 2.8 years. The OR of the WHtR was 4.51 (95\% CI, 2.418.43; $p<.0001)$ after adjusting for age, gender, smoking status, alcohol intake, regular exercise status, SBP, and total cholesterol. The mean AU-ROC of the WHtR was 
Table 2 Odds ratio of new-onset hypertension, according to the waist-to-height ratio

\begin{tabular}{llllll}
\hline & Quartile 1 & Quartile 2 & Quartile 3 & Quartile 4 & $\geq 0.5440$ \\
\hline WHtR & $<0.4752$ & $0.4752-0.5083$ & $0.5083-0.5440$ & 429 \\
No. of participants & 432 & 427 & 430 & $60(13.95 \%)$ & $73(17.02 \%)$ \\
Incidence & $13(3.01 \%)$ & $39(9.13 \%)$ & $5.23(2.82-9.67)$ & $6.61(3.60-12.12)$ & $<.0001$ \\
$\quad$ Crude OR & 1 & $3.24(1.70-6.16)$ & $4.47(2.41-8.32)$ & $5.51(2.98-10.19)$ & $<.0001$ \\
Model 1 & 1 & $2.99(1.57-5.71)$ & $4.36(2.34-8.13)$ & $5.00(2.69-9.30)$ & $<.0001$ \\
Model 2 & 1 & $2.95(1.54-5.63)$ & $4.04(2.16-7.57)$ & $4.51(2.41-8.43)$ & $<.0001$ \\
\hline
\end{tabular}

Results are described as odds ratios and 95\% confidence intervals. Model 1 was adjusted for age and gender; Model 2 was adjusted for age, gender, smoking status, alcohol intake, and regular exercise; Model 3 was adjusted for age, gender, smoking status, alcohol intake, regular exercise, SBP, and total cholesterol at the baseline

higher than that of the BMI (AUC $=0.662 ; 95 \% \mathrm{CI}$, 0.625 0.700, $p=0.0233$ ).

Diverse anthropometric indices have been developed to identify the risk factors of CVDs, especially hypertension, diabetes, and obesity. However, till date, no definitive measurement tools or indices have been developed for the prediction of hypertension. The most conventionally perceived anthropometric index is the BMI, owing to its simplicity $[21,22]$. However, the BMI cannot differentiate between individuals with excess fat and those with a high muscle mass, and cannot discriminate the location of fat; thus, based on the BMI alone, such individuals would be perceived as having the same risk for the development of CVDs [10, 23]. WC is strongly associated with visceral fat depots [24] and is now widely used in the measurement of abdominal obesity [21]. However, WC has a critical point in its use owing to its high collinearity with weight and BMI; thus, its role in the prediction of mortality and health risks is limited [21]. In particular, WC does not take into consideration differences in height. Several studies have demonstrated that individuals with the same WC but different heights are unlikely to have the same cardiometabolic risks [10]. The early detection of hypertension is crucial for its control and prevention, in adults; however, since BP is not routinely tested in most adolescents, it is difficult to monitor the condition in them $[11,25]$. Recently, the WHtR was shown to be the most important predictor of BP and hypertension, in Saudi Arabian adult populations [26]. Many studies have also focused on the changes in the values of anthropometric indices such as BMI and WC

Table 3 Receiver operating characteristic curve analysis for identifying multiple risk factors

\begin{tabular}{lll}
\hline & AUC $(95 \% \mathrm{Cl})$ & $p$ \\
\hline Weight $(\mathrm{kg})$ & $0.609(0.567 \sim 0.651)$ & - \\
BMl & $0.623(0.582 \sim 0.664)$ & 0.3829 \\
WHR & $0.648(0.608 \sim 0.688)$ & 0.0803 \\
WHtR & $0.662(0.625 \sim 0.700)$ & 0.0233
\end{tabular}

$B M I$ body mass index, WHtR waist-to-height ratio, AUC area under the curve, $\mathrm{Cl}$ confidence interval between men and women, adults and children, and Asian and non-Asian populations [10, 12, 27]. In contrast, WHtR values have been demonstrated to be steady, across age groups, gender, and ethnicities, and are even easier to measure than BMI [12, 27].

Previously conducted cross-sectional studies showed that BMI, WC, and WHR or WHtR were equally associated with the prevalence of hypertension in both genders; however, in other reports, WC was demonstrated to be the single best predictor of hypertension [2, 8, 28-30]. Various prospective studies revealed the association of BMI, a measure of overall obesity, and hypertension [31, 32], while other follow-up studies investigated the WC, WHtR, and WHR, measurements in the case of abdominal adiposity, and found them to be significantly associated with the risk of hypertension [3]. A systematic review and meta-analysis demonstrated that WHtR was a better biomarker for hypertension and CVD risk in both genders, across nationalities and ethnic groups $[10,12]$. Like in the

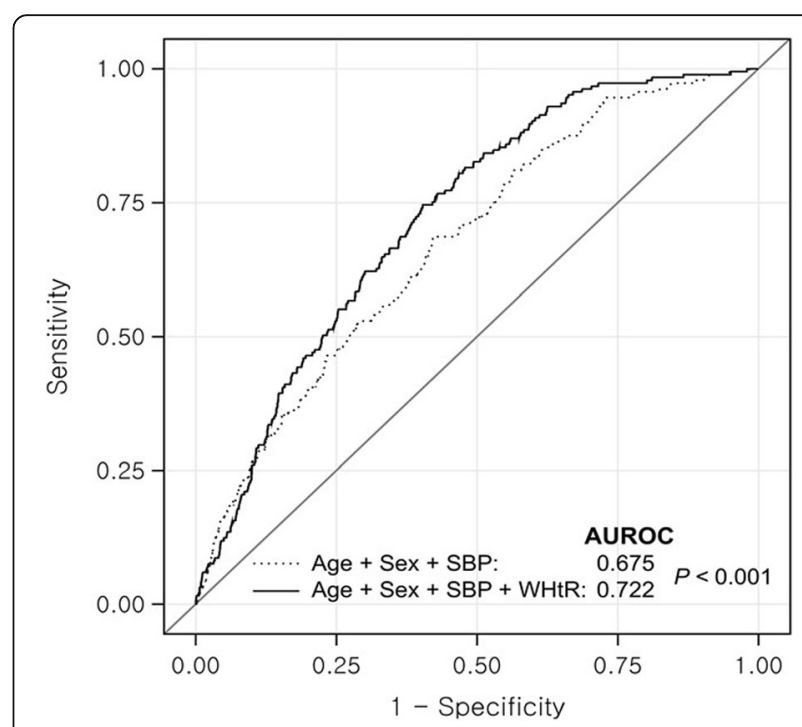

Fig. 2 Adjunctive contribution of WHtR to the development of hypertension beyond the information provided by classic risk factors 
case of the aforementioned studies, in the present study too the WHtR was found to be a significant indicator for the incidence of hypertension. However, there are still no absolute measuring tools or indices for the prediction of the incidences of hypertension, regardless of age, gender, and ethnicity, and limited data have been obtained from the prospective studies which focused on the incremental predictive value of the WHtR for the onset of hypertension. In our study, an increasing WHtR was found to be correlated with a consistent increase in the onset of hypertension. Therefore, it is suggested that the WHtR may be a better predicting biomarker for the incidence of hypertension than BMI, and may play a major role in the future diagnosis of hypertension in Korean adults.

Recently, the recommended WHtR value for the prediction of diabetes, cardiovascular disease, hypertension, and metabolic syndrome was set at 0.5 . In non-overweight Korean adolescents, a higher prevalence of multiple cardiometabolic risk factors and metabolic syndrome was observed in the WHtR $\geq 0.5$ group than the $\mathrm{WHtR}<0.5$ group [8]. In addition, while the cut-off value for diabetes was estimated to be $0.52-0.53$, the corresponding value for hypertension was found to be $\geq 0.5$; these findings are consistent with those of previously conducted studies (data not shown). The mean AU-ROC of the WHtR was higher than that of the BMI (AUC $=0.662 ; 95 \% \mathrm{CI}, 0.625 \sim 0.700$, $p=0.0233$ ). (Table 3). In this study, we measured the anthropometric indices and the diverse parameters that affect the metabolic health status, such as baseline fasting glucose and lipid profiles, in 1718 healthy Korean adults. We then evaluated the development of hypertension after 2.8 years of follow-up.

This study had some limitations. First, the number of participants who developed hypertension after 2.8 years of follow-up was relatively small. Second, the study population was limited to adults from rural areas, and, thus, does not represent the overall Korean population. Third, selection bias could have been present as our study was retrospective in nature.

\section{Conclusion}

The findings of our study suggest that the baseline WHtR is a strong predictor of hypertension in Korean populations. In addition, the WHtR was found to have several advantages as a screening measurement tool, compared to BMI. Intensive lifestyle modifications should be introduced early to reduce the WC to less than half of the height in order to reduce the risk of hypertension. Future studies conducted on large, diverse populations are required to validate the clinical applications of the WHtR.

\section{Funding}

This research was supported by the Basic Science Research Program through the National Research Foundation of Korea (NRF), funded by the Ministry of Education (2017R1D1A3B03034119).
This study was supported by the Korea Centers for Disease Control and Prevention (2005-E71013-00, 2006-E71002-00, 2007-E71013-00, 2008-E71004-00, 2009-E71006-00, and 2010-E71003-00).

This research was also supported by the Medical Research Center Program 2017R1A5A2015369.

\section{Availability of data and materials}

The datasets generated and/or analyzed during the current study are available in the Korea National Institute of Health $(\mathrm{KNIH})$ repository (http://www.nih.go.kr/NIH_NEW/main.jsp).

\section{Authors' contributions}

All authors are responsible for the design of the work. JRC performed the data analysis and drafted the manuscript. SBK and EC provided a critical review of the data analysis and manuscript. All authors read and approved the final manuscript.

\section{Ethics approval and consent to participate}

This study was approved by the Institutional Review Board of the Wonju Christian Hospital, according to the Helsinki Declaration. All the participants provided informed written consent.

Consent for publication

Not applicable.

Competing interests

The authors declare that they have no competing interests.

\section{Publisher's Note}

Springer Nature remains neutral with regard to jurisdictional claims in published maps and institutional affiliations.

\section{Author details}

${ }^{1}$ Institute of Genomic Cohort, Yonsei University Wonju College of Medicine, Wonju, Republic of Korea. ${ }^{2}$ Department of Preventive Medicine, Yonsei University Wonju College of Medicine, Wonju, Republic of Korea. ${ }^{3}$ Institute of Lifestyle Medicine, Yonsei University Wonju College of Medicine, Wonju, Republic of Korea.

Received: 4 September 2017 Accepted: 3 June 2018

Published online: 19 June 2018

\section{References}

1. Chung $\mathrm{H}$, Park S, Park MJ, Yoo EG. Waist-to-height ratio as an index for Cardiometabolic risk in adolescents: results from the 1998-2008 KNHANES. Yonsei Med J. 2016;57(3):658-63.

2. Chei $\mathrm{CL}$, Iso H, Yamagishi $\mathrm{K}$, Tanigawa $\mathrm{T}$, Cui $\mathrm{R}$, Imano H, Kiyama M, Kitamura A, Sato S, Shimamoto T. Body fat distribution and the risk of hypertension and diabetes among Japanese men and women. Hypertens Res. 2008;31(5):851-7.

3. Fuchs FD, Gus M, Moreira LB, Moraes RS, Wiehe M, Pereira GM, Fuchs SC. Anthropometric indices and the incidence of hypertension: a comparative analysis. Obes Res. 2005;13(9):1515-7.

4. Zhou Z, Hu D, Chen J. Association between obesity indices and blood pressure or hypertension: which index is the best? Public Health Nutr. 2009; 12(8):1061-71.

5. Doll S, Paccaud F, Bovet P, Burnier M, Wietlisbach V. Body mass index, abdominal adiposity and blood pressure: consistency of their association across developing and developed countries. Int J Obes Relat Metab Disord. 2002;26(1):48-57.

6. Hsieh SD, Muto T. The superiority of waist-to-height ratio as an anthropometric index to evaluate clustering of coronary risk factors among non-obese men and women. Prev Med. 2005;40(2):216-20.

7. Ho SC, Chen YM, Woo JL, Leung SS, Lam TH, Janus ED. Association between simple anthropometric indices and cardiovascular risk factors. Int J Obes Relat Metab Disord. 2001;25(11):1689-97.

8. Dobbelsteyn CJ, Joffres MR, MacLean DR, Flowerdew G. A comparative evaluation of waist circumference, waist-to-hip ratio and body mass index as indicators of cardiovascular risk factors. The Canadian Heart Health Surveys. Int J Obes Relat Metab Disord. 2001;25(5):652-61. 
9. Hsieh SD, Yoshinaga H, Muto T. Waist-to-height ratio, a simple and practical index for assessing central fat distribution and metabolic risk in Japanese men and women. Int J Obes Relat Metab Disord. 2003;27(5):610-6.

10. Son YJ, Kim J, Park HJ, Park SE, Park CY, Lee WY, Oh KW, Park SW, Rhee EJ. Association of Waist-Height Ratio with diabetes risk: a 4-year longitudinal retrospective study. Endocrinol Metab (Seoul). 2016;31(1):127-33.

11. Madruga JG, Moraes Silva F, Scherer Adami F. Positive association between waist-to-height ratio and hypertension in adolescents. Rev Port Cardiol. 2016;35(9):479-84

12. Browning LM, Hsieh SD, Ashwell M. A systematic review of waist-to-height ratio as a screening tool for the prediction of cardiovascular disease and diabetes: 0.5 could be a suitable global boundary value. Nutr Res Rev. 2010;23(2):247-69.

13. Khoury M, Manlhiot C, McCrindle BW. Role of the waist/height ratio in the cardiometabolic risk assessment of children classified by body mass index. J Am Coll Cardiol. 2013;62(8):742-51.

14. Maffeis C, Banzato C, Talamini G. Waist-to-height ratio, a useful index to identify high metabolic risk in overweight children. J Pediatr. 2008;152(2): 207-13.

15. Ashwell M, Hsieh SD. Six reasons why the waist-to-height ratio is a rapid and effective global indicator for health risks of obesity and how its use could simplify the international public health message on obesity. Int J Food Sci Nutr. 2005;56(5):303-7.

16. Rosenthal AD, Jin F, Shu XO, Yang G, Elasy TA, Chow WH, Ji BT, Xu HX, Li Q, Gao YT, et al. Body fat distribution and risk of diabetes among Chinese women. Int J Obes Relat Metab Disord. 2004;28(4):594-9.

17. Tulloch-Reid MK, Williams DE, Looker HC, Hanson RL, Knowler WC. Do measures of body fat distribution provide information on the risk of type 2 diabetes in addition to measures of general obesity? Comparison of anthropometric predictors of type 2 diabetes in pima Indians. Diabetes Care. 2003;26(9):2556-61

18. Bohr AD, Laurson $K$, McQueen MB. A novel cutoff for the waist-to-height ratio predicting metabolic syndrome in young American adults. BMC Public Health. 2016;16:295.

19. Savva SC, Lamnisos D, Kafatos AG. Predicting cardiometabolic risk: waist-to-height ratio or BMI. A meta-analysis. Diabetes Metab Syndr Obes. 2013;6:403-19.

20. Choi JR, Ahn SV, Kim JY, Koh SB, Choi EH, Lee GY, Jang YE. Comparison of various anthropometric indices for the identification of a predictor of incident hypertension: the ARIRANG study. J Hum Hypertens. 2018;32(4): 294-300.

21. Chung W, Park CG, Ryu OH. Association of a new Measure of obesity with hypertension and health-related quality of life. PLoS One. 2016;11(5):e0155399.

22. Oreopoulos A, Padwal R, McAlister FA, Ezekowitz J, Sharma AM, KalantarZadeh K, Fonarow GC, Norris CM. Association between obesity and healthrelated quality of life in patients with coronary artery disease. Int J Obes. 2010;34(9):1434-41.

23. Heymsfield SB, Scherzer R, Pietrobelli A, Lewis CE, Grunfeld C. Body mass index as a phenotypic expression of adiposity: quantitative contribution of muscularity in a population-based sample. Int J Obes. 2009;33(12):1363-73.

24. Pouliot MC, Despres JP, Lemieux S, Moorjani S, Bouchard C, Tremblay A, Nadeau A, Lupien PJ. Waist circumference and abdominal sagittal diameter: best simple anthropometric indexes of abdominal visceral adipose tissue accumulation and related cardiovascular risk in men and women. Am J Cardiol. 1994;73(7):460-8.

25. Beck CC, Lopes Ada S, Pitanga FJ. Anthropometric indicators as predictors of high blood pressure in adolescents. Arq Bras Cardiol. 2011;96(2):126-33.

26. Saeed AA, Al-Hamdan NA. Anthropometric risk factors and predictors of hypertension among Saudi adult population - a national survey. J Epidemiol Glob Health. 2013;3(4):197-204.

27. Ashwell M, Gunn P, Gibson S. Waist-to-height ratio is a better screening tool than waist circumference and BMI for adult cardiometabolic risk factors: systematic review and meta-analysis. Obes Rev. 2012;13(3):275-86

28. Ko GT, Chan JC, Woo J, Lau E, Yeung VT, Chow CC, Wai HP, Li JK, So WY, Cockram CS. Simple anthropometric indexes and cardiovascular risk factors in Chinese. Int J Obes Relat Metab Disord. 1997;21(11):995-1001.

29. Huang KC, Lin WY, Lee LT, Chen CY, Lo H, Hsia HH, Liu IL, Shau WY, Lin RS. Four anthropometric indices and cardiovascular risk factors in Taiwan. Int Obes Relat Metab Disord. 2002;26(8):1060-8.

30. Harris MM, Stevens J, Thomas N, Schreiner P, Folsom AR. Associations of fat distribution and obesity with hypertension in a bi-ethnic population: the
ARIC study. Atherosclerosis Risk in Communities Study. Obes Res. 2000;8(7): 516-24.

31. Jousilahti P, Tuomilehto J, Vartiainen E, Pekkanen J, Puska P. Body weight, cardiovascular risk factors, and coronary mortality. 15-year follow-up of middle-aged men and women in eastern Finland. Circulation. 1996;93(7): 1372-9.

32. Wilson PW, D'Agostino RB, Sullivan L, Parise H, Kannel WB. Overweight and obesity as determinants of cardiovascular risk: the Framingham experience. Arch Intern Med. 2002;162(16):1867-72.

\section{Ready to submit your research? Choose BMC and benefit from:}

- fast, convenient online submission

- thorough peer review by experienced researchers in your field

- rapid publication on acceptance

- support for research data, including large and complex data types

- gold Open Access which fosters wider collaboration and increased citations

- maximum visibility for your research: over $100 \mathrm{M}$ website views per year

At BMC, research is always in progress.

Learn more biomedcentral.com/submissions 